\title{
Charles Capper
}

The former and current co-editors dedicate this issue to the memory of Charles Capper, who passed away on 1st July, 2021. Charlie was one of the founding editors of $M I H$, alongside Nicholas Phillipson (d. 24 January, 2018) and Anthony LaVopa. Even after he stepped away from editorial duties, he remained a vibrant presence for us, embodying a generous vision of the life of the mind that he had done so much to illustrate in his own work on modern American intellectual history. A wonderful scholar and a warm friend, Charlie will be missed dearly by all who knew and worked with him. Readers who might like to remind themselves of the extent of his scholarly achievements and some of the lesser-known political dimensions of Charlie's career, can easily turn to David Hollinger's assessment in 'Charles Capper, Romantic America, and Intellectual History,' in Modern Intellectual History 16/1 (2019), pp. 281-293. 